desirable but cited overworking of existing staff as the main reason for not starting them. Most of them did not think that reimbursement of part of the cost of ancillary staff would influence this decision, though the marked increase in appointment systems since January suggests that this was a rationalization of their reluctance to take the plunge. Patients showed a similar conservatism. Their satisfaction with the status quo, noted elsewhere by Ann Cartwright, ${ }^{2}$ was reflected by the far less favourable reaction to the idea of appointment systems by patients of doctors who did not have them. Once they had experienced a successful system patients were overwhelmingly in favour of it, probably because in the average practice it halved their waiting time.

In quantitative terms the degree of success of an appointment system can be measured by the proportion of patients actually making appointments and the proportion failing to keep them. These figures varied in the practices studied from $45 \%$ to $96 \%$ and from $0 \%$ to $7 \%$, respectively. Most patients were punctual, and of the $10 \%$ who were not only a third were more than five minutes late. As Dr. Stuart Carne points out at page 544 of this week's B.M.F., an appointment system can also work in a practice with a high proportion of West Indian and West African immigrants, who on the whole are not such good timekeepers as the English and Irish patients.

The success of any system depends to a large extent on the organizing ability of the receptionists and their attitude to patients. They need to be present during all surgery sessions at least, and, on average, staff time must be increased by ten to twelve hours per week per doctor in a partnership and twice as much in a single-handed practice. Success depends also on estimating beforehand the doctor's consultation time-which may differ for each doctor in a partnership - and scheduling appointments accordingly. Doctors must be punctual themselves, because patients who repeatedly have to wait long after their appointment time get disillusioned and stop making appointments.

One of the changes which would help fewer practitioners to care effectively for more patients would be an increase in the ratio of surgery consultations to home visits. The figures from the practices, admittedly small in number, which kept records before and after an appointment system did not show any such increase, though more detailed data and a more rigorous analysis would have been needed to detect any but a very large one. That a consultation probably did acquire greater significance is suggested by the fact that about a quarter of the doctors questioned thought there had been a decrease in trivial consultations and an increase in non-trivial ones. But if an appointment system does not in itself persuade patients to come to the surgery instead of asking for a home visit it is an essential prerequisite for other means of achieving that end: by having a doctor consulting throughout the day as J. S. K. Stevenson ${ }^{3}$ found ; or by receptionists pointing out the convenience of a surgery attendance at a particular time for the patient himself as well as for his doctor, as Andrew Smith ${ }^{4}$ has suggested.

What does emerge quite clearly from the investigation is that it is worth while for every type of practice, except probably a single-handed one, to run a system in which all sessions are by appointment and all patients are encouraged to make an appointment.

\footnotetext{
1 Bevan, J. M., and Draper, G. J., Appointment Systems in General Practice, 1967, London. Oxford University Press, price 12s. 6d. - Cartwright, Ann, Patients and their Doctors, 1967. London.

- Stevenson, J. S. K., Brit. med. Y., 1966, 2, 515.

- Smith, A., ibid., 1967, 2, 369.
}

\section{Reappraisal of the Austin Flint Murmur}

When Alice, in Through the Looking-glass, was trying to reach a particular hill she found that the only way to reach her destination was to turn her back on it and walk in the opposite direction. Something of the same kind seems to be happening to our conception of the Austin Flint murmur.

In Austin Flint's original description of the murmur ${ }^{1}$ he suggested that the likely pathogenesis was that the mitral valve leaflets became closed in early diastole as a result of over-distension of the left ventricle from free aortic incompetence, and that during atrial systole the mitral valve reopened with accompanying vibrations of the anterior cusp, producing a characteristic blubbering murmur. Recently it has been shown that in cases of free aortic incompetence reversal of the left atrioventricular gradient takes place in late diastole, left ventricular exceeding left atrial pressure by $20 \mathrm{~mm}$. Hg or more. ${ }^{2-4}$ E. D. Wigle and C. J. Labrosse in 1965 found that an Austin Flint murmur was present in 9 out of 14 patients who developed sudden severe aortic incompetence and a reversal of the left atrioventricular diastolic pressure gradient. Clearly in these cases forward flow through the mitral valve in late diastole could not play any part in the production of the murmur. The next year H. E. Aldridge and his colleagues ${ }^{6}$ demonstrated diastolic $^{2}$ mitral insufficiency by cineangiography in nine patients with severe aortic incompetence and reversed pressure gradients. It remained for S. Lochaya, M. Igarashi, and A. B. Shaffer ${ }^{7}$ to suggest that the Austin Flint murmur commonly found in severe aortic incompetence was due to diastolic mitral incompetence. They reported three cases with cineangiographic evidence of late diastolic mitral regurgitation coinciding with an Austin Flint murmur recorded in the phonocardiogram.

Given that diastolic mitral regurgitation does indeed sometimes occur in severe cases of aortic incompetence, two further problems remain. What causes the mitral valve to become incompetent in late diastole? And are the vibrations set up by this regurgitant puff responsible for the Austin Flint murmur ? Lochaya and his colleagues ${ }^{7}$ suggest that dilatation of the mitral valve ring due to left ventricular enlargement may result in incomplete closure of the mitral orifice by the valve cusps. The normal function of the chordae tendineae might be impaired by the great ventricular dilatation, and another factor could be partial displacement of the closed or nearly closed mitral valve cusps during the atrial systole. Whether a small puff of mitral regurgitation would be sufficient to produce a loud mitral diastolic murmur is uncertain, but it is difficult to present a satisfactory alternative explanation for the murmur in patients with a reversed diastolic atrioventricular gradient.

So the Austin Flint murmur may have a different pathogenesis in individual cases of aortic incompetence, depending on the direction of the left atrioventricular diastolic pressure gradient. When the murmur occurs with less severe aortic incompetence and without reversal of the left atrioventricular

\footnotetext{
Flint, A., Amer. f. Med., Sci., 1862, 44, 29.

- Wright, J. L., Toscano-Barboza, E., and Brandenburg, R. O., Proc. Mayo Clin., 1956, 31, 120.

Welch, G. H., jun., Braunwald, E., and Sarnoff, S. J., Circulat. Res., $1957,5,546$.

- Dodge, H. T., Sandler, H., and Evans, T., Circulation, 1960, 22, 741.

- Wigle, E. D., and Labrosse, C. J., ibid., 1965, 32, 708.

- Aldridge, H.'E., Lansdown, E. L., and Wigle, E. D., ibid., 1966, 34, Suppl. No. 3, 42.

' Lochaya, S., Igarashi, M., and Shaffer, A. B., Amer. Heart F., 1967, 74, 161.
} 
diastolic pressure gradient the Austin Flint murmur could well be due to forward flow of blood through a functionally narrowed mitral valve, as originally suggested. In more severe cases, however, with a reversed pressure gradient, diastolic mitral incompetence seems to be a likely explanation of the pathogenesis of the murmur.

\section{Coal Mining, Pneumoconiosis, and Lung Cancer}

In 1936 N. M. Kennaway and E. L. Kennaway ${ }^{1}$ drew attention to the low mortality from lung cancer among coal miners as compared with the general male population. Further studies by the Kennaways ${ }^{23}$ and by other workers ${ }^{4-8}$ led to the same conclusion; and according to the Decennial Supplement of the Registrar General published in $1938^{\prime}$ the standardized mortality ratio (S.M.R.) for lung cancer in men working on the coal face for the three years, 1930-2 was 67 (compared with 100 for all males). The S.M.R. for lung cancer in underground workers in coal mines other than coalface workers was lower still-namely, 36 . In a more critical study conducted in South Wales W. R. L. James ${ }^{8}$ found lung cancer at necropsy in $5.4 \%$ of 1,531 non-miners but in only $3.3 \%$ of 1,827 coal miners. When he subdivided the miners into those with simple pneumoconiosis and those with progressive massive fibrosis (P.M.F.) the rates were $5.1 \%$ and $1.4 \%$, respectively. More recently K. P. Goldman ${ }^{9}$ has analysed unpublished data collected by the Medical Research Council's Epidemiology Unit in South Wales. These data consisted of records of radiological examinations for pneumoconiosis and information on causes of death as written on death certificates for a community of 5,096 miners and ex-miners in the Rhondda Fach Valley in Glamorganshire. The results of Goldman's analysis were somewhat in conflict with the findings of $\mathrm{James}^{8}$ : the mortality from lung cancer was highest, and equal to the national average, among miners with P.M.F., lowest in those with simple pneumoconiosis, and intermediate in those free of radiological evidence of dust disease.

Both James ${ }^{8}$ and R. A. Smith ${ }^{10}$ reported that survival rates are better than average in miners after surgical resection of lung cancer. Goldman ${ }^{11}$ investigated this phenomenon in a careful retrospective survey of cases of primary lung cancer who attended the regional thoracic centre for South Wales between 1954 and 1960. The case material included 172 miners and 518 non-miners, and was analysed according to age, sex, smoking habits, length of time symptoms were present, respiratory function, tumour histology, method of treatment, and survival. In addition, the 172 miners were classified according to degree of pneumoconiosis as assessed radiologically. The miners as a group had a slightly reduced forced expiratory volume (F.E.V.), but differences between miners and non-miners in smoking habits, length of symptoms, average age at onset of symptoms, and spectrum of tumour types were small. Similar proportions of miners and nonminers were deemed operable, but, as noted by T. F. Nealon, ${ }^{12}$ the immediate operative mortality was higher in the former. Survival during the five years after operation or diagnosis was similar in miners and non-miners, both for the inoperable cases and for the surgically treated cases who survived the first 28 days after operation. However, among miners, whether treated by surgery or not, survival time during the two years after diagnosis increased with the severity of simple pneumoconiosis as determined radiologically.

It has been suggested ${ }^{1011}$ that this better survival from lung cancer in the presence of pneumoconiosis may be due to the blockage of lymphatics by fibrosis and particle-laden macrophages, ${ }^{13}$ which serves to prevent the dissemination of cancer cells. It would be tempting to argue that the same factor could be responsible for the reduced incidence of clinically recognized lung cancers in miners, but this is unlikely in so far as Goldman found evidence of better survival from the disease only in the minority of miners with the more severe grades of simple pneumoconiosis. A mere excess of coal dust in the lungs in the absence of radiological evidence of pneumoconiosis did not affect survival time.

The difficulties of studies of this kind can scarcely be exaggerated. For instance, the diagnosis of lung cancer is rendered difficult by the presonce of pneumoconiosis. ${ }^{12} 14$ is A miner, particularly a pneumoconiotic, is more likely than a non-miner to be under radiological surveillance, with the result that lung cancer may be diagnosed earlier. Also one must question whether sufficient account has been taken of exposure to tobacco smoke. It is true that many workers ${ }^{16-21}$ have either failed to find much difference between miners and non-miners in relation to their smoking habits or have observed that the smoking habit is more prevalent among miners than in the general population. However, the results of three surveys ${ }^{17-19}$ indicated that the proportion of miners who are heavy smokers is lower than for the general population. Furthermore, according to G. F. Todd, ${ }^{22}$ though miners were smoking more than the average for all social classes in 1958, the position was reversed by 1961 . An underground worker is precluded from smoking during most of his working day. The accumulated effect of these differences might be important in relation to the lowered incidence of, and better survival from, lung cancer in miners.

D. J. B. Ashley ${ }^{23}$ has recently drawn attention to an excessive mortality from bronchitis and a reduced mortality from lung cancer in areas of England and Wales where coal mining and textile industries are prominent. He excludes the possibility that differences in exposure to general air pollutants may be responsible, but does not consider the

Kennaway, N. M., and Kennaway, E. L., F. Hyg. (Lond.), 1936, 36, 236.

2 Kennaway, E. L., and Kennaway, N. M., Brit. F. Cancer, 1947, 1, 260.

ibid., 1953, 7, 10.

Gooding, C. G., Lancet, 1946, 2, 891.

McVittie, J. C., Postgrad. med. F., 1949, 25, 618

- Chatgidakis, C.’ B., Brit. F. industr. Med., 1963, 20, 236.

Registrar General, Decennial Supplement, England and Wales 1931, Part II a, Occupational Mortality, 1938. H.M.S.O., London.

James, W. R. L., Brit. F. industr. Med., 1955, 12, 87.

- Goldman, K. P.; ibid., 1965, 22, 72.

10 Smith, R. A., ibid., 1959, 16, 318.

11 Goldman, K. P., Thorax, 1965, 20, 170.

12 Nealon, T. F., Arch. environ. Hlth, 1964, 8, 882.

18 Heppleston, A. G., F. Path. Bact., 1947, 59, 453.

14 Goldman, K. P., Brit. Ұ. Dis. Chest, 1965, 59, 141.

is Gernez-Rieux, "C., Voisin, C., Balgairies, E., Delepoulle, E., and Lenoir, L., Lille méd., 1961, 6, 551.

16 Higgins, I. T. T., Oldham, P. D., Cochrane, A. L., and Gilson, J. C., Brit. med. F., 1956, 2, 904.

17 and Cochrane, A. L., Brit. F. industr. Med., 1961, 18, 93.

is Ashford, J. R., Brown, S., Duffieid, D. P., Smith, C. S., and Fay, J. W. J., Brit. Ұ. prev. soc. Med., 1961, 15, 106.

19 Todd, G. F., Statistics and Smoking, Research Papers No. 1, 2nd edition, Tobacco Manufacturers Standing Committee, 1959. edition,

20 Cross, K. W., McDowell, L. A., and Posner, E., Brit. med. F., 1958,

21 Brown, S., Report No. Sc 849/MR/41, National Coal Board Scientific Department, 1962 . London.

22 Todd, G. F, Statistics of Smoking, Research Papers, No. 1, 3rd edition, Tobacco Research Council, 1962. London.

23 Ashley, D. J. B., Brit. Y. Cancer, 1967, 21, 243.

24 Old, L. L., Benacerraf, B., Clarke, D. A., Carswell, E. A., and Stockert, E., Cancer Res., 1961, 21, 1281. 